\title{
Benzeduras, garrafadas e costuras: considerações sobre a prática da benzeção
}

\author{
Benzeduras, potions, and seams: practical considerations on the benzeção
}

\author{
Marisete T. Hoffmann-Horochovski ${ }^{1}$
}

\begin{abstract}
Resumo
O presente artigo versa sobre a benzeção, que sobrevive em tempos atuais apesar da hegemonia do pensamento biomédico. Associada ao catolicismo popular, essa tradicional prática de cura é transmitida de geração a geração por pessoas que acreditam terem recebido um dom divino e que se dedicam a ajudar os outros, tratando males do corpo e da alma. A partir de relatos orais, benzedeiras do litoral paranaense possibilitaram entender mais sobre a prática da benzeção, os rituais que a envolvem e as doenças que trata. Prática que faz parte da cultura imaterial e que tem sido alvo de movimentos de resgate e valorização, embora ainda corra o risco de desaparecer, especialmente nas grandes cidades.
\end{abstract}

Palavras-chave: Benzeção; Cura; Saber popular.

\begin{abstract}
This article deals with the benzeção, which survives in modern times despite the hegemony of biomedical thought. Associated with popular Catholicism, this traditional healing practice is transmitted from generation to generation by people who believe they have received a divine gift and who are dedicated to helping other and treating ailments of body and soul. Through their oral stories traditional healers from coast of Paraná enabled to understand better the practice of benzeção, rituals that surround it, and diseases they treat. This practice is part of immaterial culture and it has been target of a rescue and recovery movement, though it is still in danger of disappearing especially in big cities.
\end{abstract}

Keywords: Benzeção, cure, folk knowledge.

\section{Introdução}

O benzimento foi, e ainda é em muitos lugares, uma prática de cura bastante difundida e reconhecida socialmente. Atividade antiga na sociedade brasileira, remonta ao Brasil colonial, envolve saberes populares que são transmitidos de geração a geração e é realizada principalmente, mas não exclusivamente, por mulheres que a assumem como uma vocação.

1 Doutora em Sociologia (UFPR). Professora do Programa de Pós-Graduação em Desenvolvimento Territorial Sustentável da Universidade Federal do Paraná. E-mail: marisetehh@gmail.com. 
Geralmente, a prática é aprendida de duas formas: intuitivamente ou por ensinamentos recebidos de alguém mais velho que procura garantir a manutenção de seus conhecimentos, a continuidade de suas rezas. Em ambos os casos, contudo, considera-se que a pessoa aprendiz é agraciada com um dom divino e é justamente isso que a torna apta a realizar os procedimentos de cura. Seu caráter sagrado, comumente associado ao catolicismo popular, está relacionado com sua finalidade de curar doenças, males que são provenientes do corpo e do espírito (SANTOS, 2007; SILVA, 2009).

Nas primeiras décadas do século XXI é possível identificar dois movimentos contrários no que tange a essa antiga prática. De um lado, o avanço constante da técnica e da ciência na área médica, a supremacia do conhecimento biomédico e a universalização da saúde, especialmente nas grandes cidades, contribuem para a diminuição e enfraquecimento dessa expressão da medicina popular, a ponto de se questionar se estará ela condenada a desaparecer com a morte das velhas benzedeiras (HOFFMANN-HOROCHOVSKI, 2012). Do outro, trabalhos de resgate dessa atividade, considerada cultura imaterial, e estudos crescentes, em diferentes áreas, sobre saberes populares que tradicionalmente são utilizados no tratamento e cura de doenças parecem apontar não só para sua manutenção quanto para sua valorização. A título de exemplo, cita-se o Movimento Aprendizes da Sabedoria (Masa) e a Etnobotânica. O primeiro, formado por pessoas que conhecem e praticam a medicina popular, conseguiu, entre outros feitos, o reconhecimento oficial da prática de benzeção nas cidades paranaenses de São João do Triunfo e Rebouças (SILVA, 2012). A segunda, por sua vez, se consolida como um campo interdisciplinar que estuda o uso, o manejo e o significado cultural das plantas medicinais nos diferentes grupos sociais (MACIEL; GUARIM NETO, 2006; PASA, 2011).

É neste cenário, aparentemente contraditório, que se procura tecer algumas considerações sobre essa prática de cura, que sempre possibilitou formas de interação e sociabilidade entre os membros de um determinado grupo social e que diz muito a respeito da história desse grupo. O que é benzimento? Quais os rituais que o envolvem? Quem os pratica? Que doenças costuma tratar? Há "doenças de médico" e "doenças de benzedeiras"? Possui eficácia simbólica? Está fadada a desaparecer ou a se fortalecer em tempos hodiernos? Essas e outras questões motivaram as reflexões aqui expostas, que estão ancoradas em entrevistas e observações realizadas com benzedeiras no litoral paranaense. 


\section{Metodologia}

A pesquisa, de cunho qualitativo, parte do pressuposto que a saúde e a doença são categorias que ultrapassam fronteiras disciplinares e a racionalidade propagada pelo saber biomédico. A subjetividade e outras formas de saberes, inclusive os da medicina popular, podem e devem ser considerados em sua análise. Muitos caminhos metodológicos poderiam viabilizar esta pesquisa que visa refletir, como já dito, sobre uma antiga prática de cura imersa na cultura popular. Aqui, optou- -se por trabalhar com as memórias de quem conhece bem a prática porque a executa há muito tempo, ou seja, de quem realiza benzimentos para curar males provenientes do corpo e do espírito.

Entrelaçada à memória coletiva (HALBWACHS, 2004), a memória individual permite a reconstituição de fatos que podem ser imprescindíveis na análise da temática estabelecida. Ao lembrar, o indivíduo reconstrói acontecimentos vivenciados ao longo de sua existência; acontecimentos que estão relacionados com grupos e instituições com os quais teve contato, dentro de um determinado quadro espaço-temporal (HALBWACHS, 2004; BOSI, 2001). Ao narrar, estabelece relações e atribui significados. Esse duplo movimento possibilita a realização da pesquisa que sublinha a importância da oralidade e a indissociabilidade entre biografia e história, individual e coletivo, que legitima a pesquisa social elaborada a partir de memórias (SILVA, 1998).

Destarte, buscou-se dar voz aos pesquisados para exporem suas memórias, falarem de si, do outro, do grupo; para contarem sobre benzimento e cura, saúde e doença, vida e morte. Por meio de suas vozes a possibilidade de compreensão e registro; a viabilidade de identificar elementos de um saber popular, ancorado no sagrado, que integra a cultura imaterial da sociedade brasileira e que sobreviveu à difusão do conhecimento racionalizado (HOFFMANN-HOROCHOVSKI, 2012).

E aqui é importante registrar que as vozes desse enredo são femininas. Quatro mulheres vividas - a mais nova com 55 anos; a mais velha com 76 anos -, que iniciaram a arte de benzer quando jovens, dedicando boa parte de seu tempo e disposição para curar. Quatro mulheres com muitas histórias para contar sobre benzeduras e costuras (ritual de benzimento que simbolicamente conserta os machucados enquanto, com muita oração, um pano é alinhavado com linha branca). Três delas também têm histórias sobre garrafadas, ou seja, remédios feitos com ervas medicinais que podem ser recomendados aos que as 
procuram. Ressalta-se que o recorte de gênero não foi intencional e que essas benzedeiras foram selecionadas por serem muito conhecidas e respeitadas na região. Falam, portanto, com a legitimidade de quem muito viveu e aprendeu sobre medicina popular e com a autoridade conferida pelo reconhecimento do grupo social.

A pesquisa de campo foi realizada nas cidades de Matinhos (três benzedeiras) e Guaratuba (uma benzedeira), situadas no litoral paranaense, entre julho de 2009 e dezembro de $2012^{2}$. Além das entrevistas, que priorizaram a liberdade da narração (embora com roteiro pré-estabelecido), foi utilizada a técnica de observação que, com o auxílio do "velho e bom caderno de campo" (MAGNANI, 1997), permitiu uma maior compreensão das crenças e dos espaços de cura, bem como das representações e práticas das benzedeiras.

O litoral é uma microrregião geográfica do estado do Paraná, que possui uma área territorial de 6.333.2333 $\mathrm{Km}^{2}$ (IPARDES, 2013), distribuída entre suas sete cidades, com a maior área contínua de Floresta Atlântica do Brasil. As cidades de Matinhos e Guaratuba, localizadas ao sul da microrregião, possuem uma área territorial total de $1.445,024 \mathrm{~km}^{2}$, que abriga grande parte do Parque Nacional Saint-Hilaire Lange e da Área de Proteção Ambiental (APA) de Guaratuba, que objetivam conservar e preservar a Mata Atlântica.

Distantes pouco mais de cem quilômetros da capital Curitiba, Matinhos e Guaratuba apresentam características semelhantes, com população de 31.000 e 34.000 habitantes e Índice de Desenvolvimento Humano (IDH) de 0,743 e 0,717, respectivamente (IPARDES, 2013). Famosas por seus balneários, cada uma costuma receber mais de um milhão de turistas durante a temporada de verão, que abrange o período do Natal ao Carnaval. É claro que isso promove diversas consequências na dinâmica local, entre as quais, a sazonalidade do trabalho. As inúmeras oportunidades presentes no verão contrastam com as dificuldades vividas nas outras estações do ano, promovendo levas migratórias (de e para) outras localidades, a exemplo da Região Metropolitana de Curitiba (RMC). De forma geral, o mercado imobiliário, a construção civil e serviços se destacam entre as principais atividades econômicas das duas cidades (CHEMIN, 2011).

Neste cenário, a dinamicidade e a diversidade imprimem suas marcas no meio ambiente e na sociedade, traduzindo riqueza na fauna e flora e nos grupos sociais, dentre os quais, inúmeras comunidades tradicionais. O trabalho artesanal, de subsistência, os saberes

2 A pesquisa de campo contou com a colaboração de Mirna Carriel Cleto e Lauana Perez, ex-alunas do Curso de Serviço Social da UFPR (Setor Litoral). É importante dizer que os nomes das benzedeiras pesquisadas são fictícios. 
populares, transmitidos de geração para geração, fazem parte da cultura local, que mantém muito de seus costumes e tradições, embora conviva com mudanças promovidas pelo novo, pelo moderno.

Dito isso, é hora de ouvir as benzedeiras e tecer algumas considerações sobre suas práticas de cura, isto é, sobre benzeduras, garrafadas e costuras.

\title{
A prática da benzeção
}

Benzer para proteger, fortalecer e curar. Durante muito tempo era a alternativa para boa parte da população, distante geográfica e socialmente dos centros urbanos, onde se consolidava o saber médico moderno. Em paragens interioranas o benzimento e outras formas de conhecimento popular cumpriam a função de tratar doenças, males do corpo e da alma.

\begin{abstract}
A população das cidades interioranas espalhadas pelos espaços rurais desenvolveriam, pela tradição, formas próprias de intervir no corpo doente, no corpo que sofre fisicamente. A intermediação entre o paciente e o seu problema poderia ocorrer através da figura ampliada do curador, seja ele o benzedor ou aquele que indica mezinhas, chás e receitas conhecidas, aquele que observa, diagnostica e prescreve ou, ainda, por meio de alguns elementos que podem representar proteção: patuás e amuletos espalhados pelo corpo, ou outras formas de crença (FIGUEIREDO, 2008, p. 21).
\end{abstract}

O relato é de Minas Gerais nos idos de mil e oitocentos, mas pode ser estendido temporal e espacialmente para outras regiões do Brasil, principalmente as que distam das grandes cidades. Nelas, a assim chamada "arte de curar", alicerçada na crença no sagrado e em saberes transmitidos geracionalmente, era bastante difundida e utilizada.

Apesar do século XIX ser, de acordo com Figueiredo (2008), "um marco na história da medicina" - presenciando a descoberta e o uso da anestesia nas intervenções cirúrgicas e de práticas de assepsia, bem como progresso nas pesquisas bacteriológicas -, não conseguiu alterar esse cenário. Sem conseguir coibir, passa a conviver com a medicina popular.

O espaço da fé, da crença, da simpatia não se contrapõe, na prática das pessoas do século XIX, ao espaço da razão e da chamada ciência médica. Aquele que procura o curandeiro pode, para o mesmo problema, consultar o médico formado. Encontramos relatos de médicos indicando que os pacientes passavam pelas mãos de outros curadores e procuravam os 
médicos quando não obtinham sucesso na primeira tentativa (FIGUEIREDO, 2008, p. 31).

No decorrer do século XX o saber biomédico, hospitalocêntrico, racionalizado e especializado, passou a dominar de forma absoluta. Outras formas de saberes vão gradativamente perdendo espaço no diagnóstico e tratamento de doenças. Com a criação do Sistema Único de Saúde - SUS (LEI n 8080/1990) - que tem como princípios norteadores a universalidade, a integralidade e a equidade -, a medicina formal se torna teoricamente acessível a todos. Tudo parece indicar que no limiar do século XXI a medicina popular está fadada a desaparecer. Afinal, se é possível consultar um médico, utilizar recursos terapêuticos com tecnologia de ponta, tratar com medicamentos avançados, por que procurar outras formas de saberes? Por que se benzer, costurar, utilizar garrafadas ou outros tipos de procedimentos tradicionais de cura que aparentemente não podem ser explicados sob uma ótica racional?

Todavia, esse desaparecimento não se concretizou. A medicina popular e especificamente a prática de benzeção sobrevive em diferentes espaços geográficos. Em regiões mais afastadas, interioranas e mesmo nas periferias das grandes cidades, é comum encontrar benzedeiras, por exemplo, que dedicam boa parte de seu tempo ao ofício da cura; à atividade de ajudar os outros a superarem suas doenças corporais e espirituais. Algumas são rezadeiras no sentido estrito; benzem com água (benta ou não) e ramos verdes, recitando orações específicas para cada doença. Outras, além de benzer, receitam chás, banhos curativos e/ou para afastar energias negativas, "preparados", entre outros (SANTOS, 2007; SILVA, 2009, HOFFMANN-HOROCHOVSKI, 2012). Neste caso, além da crença no sagrado, acredita-se no uso das plantas para curar doenças na assim chamada "medicina não oficial da cultura brasileira" (MACIEL; GUARIM NETO, 2006). Em que pese diferenças entre os rituais e as crenças, todas as pessoas que praticam a benzeção se consideram detentoras de um dom divino, que as qualificam e as identificam como benzedeiras ou curandeiras.

\section{O dom}

A atividade de benzeção é alicerçada no sagrado. Benzer não é exatamente uma escolha; é antes uma obrigação. Quem o faz acredita piamente que recebeu um dom divino e que, por isso mesmo, precisa retribuir, auxiliando os outros em suas dificuldades. O dom pode ser revelado por um acontecimento "sobrenatural", como uma visão, um sonho ou a superação de um grande obstáculo, ou ainda pode ser detectado por uma benzedeira mais velha que 
transmite oralmente seu conhecimento para garantir a continuidade da prática (ARAÚJO, 2011; SANTOS, 2007). As duas situações foram identificadas entre as pesquisadas.

Natália, 76 anos, começou a benzer com 12 anos de idade seguindo uma orientação sagrada, uma voz que lhe ordenou que pegasse a caneca com água benta utilizada por seu pai e benzesse um rapaz que estava com cobreiro na orelha. "Eu fui no quarto peguei a canequinha, peguei água do quarto e benzi. No outro dia o rapaz estava são com a graça de Deus, e daí por fim um foi contando pro outro, e eu fui benzendo...”. Seu pai era benzedor e isso obviamente a influenciou, mas ele nunca lhe ensinou. Católica, aprendeu sozinha, ou melhor, seguindo essa voz espiritual que lhe dizia o que e como fazer: "É um dom que Deus me deu” (Natália). E com essa afirmação justifica não só sua iniciação, mas como fez a opção de viver em prol dos outros, ajudando todos que a procuram sem nenhuma distinção.

A oração e a fé em São Jorge e em Nossa Senhora de Fátima fizeram com que Diana, 55 anos, ajudasse num parto delicado com pouco mais de 20 anos de idade.

Eu tinha muito medo [...] Daí eu fui rezar e nisso veio pra mim essa força e eu fui atender ela. Nasceu o nenê e foi dito, foi dito no meu ouvido: ela não vai durar sete dias; ele só veio visitar o mundo. E na verdade foi verdade. Foi dali em diante que eu comecei a benzer, fazer garrafada, curar... muita gente já se curaram na minha mão. Benzer nenezinho que chega aqui bem mal, é... da bicha, da bronquite e sai daqui sorrindo graças a Deus (Diana).

O parto e seu desfecho, ocorrido há mais de trinta e dois anos, modificaram significativamente sua vida: assumiu sua fé e seu dom e passou a ajudar o próximo, benzendo em nome de Deus! Declaradamente feliz, conta que agradece todos os dias por ter sido contemplada com esse dom.

Manuela e Mariana aprenderam o benzimento com pessoas mais velhas, que lhes escolheram como aprendizes, respectivamente o pai e a madrinha. Manuela, 73 anos, narra que seu pai the ensinou "muita coisa" durante um período de dois anos, que se encerrou com a morte dele quando ela estava com 16 anos de idade. Mariana, 62 anos, aprendeu a benzer com sua madrinha, que temia morrer antes de transmitir seus conhecimentos; saberes que são tidos como fundamentais na pequena comunidade litorânea onde nasceu, cresceu e vive até hoje. Aqui, os benzedores mais velhos identificaram o dom nas jovens e as preparam para realizar rituais de cura, garantindo a manutenção da antiga prática (ARCHANJO; LEITE, 2014).

Reconhecer e aceitar a existência de um dom, de um presente divino, implica encargos, como por exemplo, não parar de benzer (SANTOS, 2007) e não cobrar nada em 
troca (LIMA, 2011). A gratuidade não impede o recebimento de doações que, não obstante, não devem ser pedidas. Elas são antes um reconhecimento de quem recebeu a benzedura e quer agradecer ou contribuir para quem dedica seu tempo para ajudar os outros. Nesse sentido, Natália conta que parou de trabalhar no comércio, pois não conseguia cuidar do armazém e do benzimento ao mesmo tempo: “ou é uma coisa ou é outra”. Aposentada por idade, enfatiza que recebe ajuda de seus clientes: "um traz um quilinho de arroz, outro traz um macarrão, o outro traz uma massa de tomate, o outro traz uma verdura, e eles me ajudam, eu não peço, eles que têm vontade" (Natália).

É mister destacar que muitas pessoas que assumem a prática da benzeção como ofício não costumam ter tempo livre para trabalhar em outras atividades, a exemplo do que sempre ocorreu com Natália. Seu tempo sempre foi dedicado aos outros e nesses casos, as doações ajudam muito na arte da sobrevivência. Mariana vive numa comunidade rural que desenvolve agricultura de subsistência e artesanato com cipós, atividades que possibilitam uma flexibilidade na medida em que ela pode parar de laborar para benzer e depois retornar, sem maiores prejuízos. A única que trabalhou no mercado formal foi Manuela, que era merendeira em uma escola estadual do litoral. Sua reza ocorria nos horários em que não estava na escola, embora costumasse fazer chás para os professores quando necessário, para acalmar ou para curar alguma dor específica.

De forma geral, tudo indica que o tempo dedicado ao ofício de benzer diminui as possibilidades de participar de outras atividades, laborais ou lúdicas. Parece igualmente que ele é praticado principalmente por mulheres, pois estas estavam comumente envolvidas com trabalhos na esfera doméstica e "teriam mais tempo" para atender seus clientes. Os registros de benzedeiros são em menor número e geralmente coincidem com regiões afastadas dos grandes centros e com o desenvolvimento de atividades artesanais, agrícolas e pesqueiras.

As doenças e os rituais de cura

O benzimento visa curar doenças oriundas, como já sublinhado, do corpo e do espírito. Mas algumas doenças são tradicionalmente tratadas por essa prática: cobreiro (irritação na pele), dor de cabeça, dor de dente, peito aberto ou arca caída (dores na região do tórax), afta, quebranto (mau-olhado), bicha (lombriga, vermes), machucadura e rendidura (dores musculares e lesão por esforço), entre outras. São as chamadas "doenças de benzedeiras" ou “doenças de rezadeiras" (SANTOS, 2007; ARAÚJO, 2011; LIMA, 2011; ARCHANJO; 
LEITE, 2014). No ritual da cura há semelhanças, mas também diferenças. Isso porque "cada benzedeira possui um rito próprio, uma maneira singular de benzer, mesmo quando se trata da mesma benzeção. Essa singularidade a torna ainda mais fascinante, uma vez que presenciamos várias maneiras de se alcançar o mesmo objetivo: a cura através da fé" (NOGUEIRA; VERSONITO; TRISTÃO, 2012, p. 169).

O caráter sagrado desta prática geralmente pode ser evidenciado no próprio ambiente de cura. Quadros e/ou imagens sacras reverenciam Jesus Cristo, Nossa Senhora e uma gama de santos protetores, reverenciados pelo catolicismo popular, que são evocados de acordo com os males averiguados. Mas a forma de professar a oração, os gestuais e as recomendações variam de acordo com cada benzedeira.

Natália, por exemplo, tem uma capela em frente ao local da benzeção para homenagear os santos. Todos os seus clientes/pacientes acendem uma ou várias velas para as divindades de acordo com suas recomendações: Sagrado Coração de Jesus, Nossa Senhora Aparecida, Nossa Senhora de Fátima, Santa Rita, São Cosme e Damião, São Cristóvão, São José figuram entre os exemplos mais recorrentes. Cada santo é responsável por uma determinada área, por assim dizer, e o número de santos (e das velas) varia de caso para caso. Quanto maior o número de santos e, respectivamente, de velas acessas, mais sério o problema detectado ou maior a necessidade de proteção. O interessante é que devido ao grande número de velas constantemente acessas na capela, ela resolveu tirar os santos de lá, para protegê-los da fuligem. Atualmente, todos estão dispostos em prateleiras no pequeno espaço onde realiza seu ofício de benzer.

A benzedura é realizada num pequeno cômodo integrado à casa, mas com abertura única para a área externa. É um espaço simples, de cura, com prateleiras de madeiras para os santos, dispostos como altares, e uma única cadeira destinada a quem vai receber a reza. Este sempre fica sentado e com as mãos abertas em cima das coxas, enquanto a benzedeira em pé inicia os procedimentos do ritual de cura, que dura no máximo cinco minutos. Com as mãos sobre a cabeça do paciente, pergunta sobre sua vida e seu trabalho, enquanto reza fervorosamente e benze com água benta e ramos verdes, habitualmente arruda. Depois disso, entrega a(s) vela(s) - recebida(s) em doação - para ser imediatamente ofertada(s) ao(s) santo(s) no espaço da capela.

Esse seu ritual básico de benzeção é geralmente efetuado uma única vez para produzir o efeito esperado. Natália afirma, porém, que "quando tá muito carregado, muito com inveja, 
daí eu peço pra vir três dias". Nestes casos o benzimento só é concluído após a reza do terceiro dia. Em outras situações que considera como sendo de muita negatividade, além das velas e das orações, recomenda banhos: de sal grosso (dos ombros para baixo), de arruda e de rosa branca. Afasta a negatividade e traz energia positiva.

Por fim, em se tratando de machucaduras ou quebraduras, é necessária a prática da costura, que segue outro procedimento ritualístico, embora muito semelhante. Em pé, mas agora segurando um pano que costura com uma agulha com fio branco, pergunta: "O que é que eu coso?". O paciente responde: "Carne rasgada, Nervos torcidos, Coluna, Quadril, Torcicolos, Pescoço, Ombros, Peito aberto, Espinhela caída, Os braços, Os fêmur, Os joelhos, As pernas e os pés. Em nome do Pai, do Filho e do Espírito Santo, Amém!” (Natália). A mesma fala é repetida três vezes e ao seu término a "costura" é concluída com a entoação de um Pai Nosso e uma Ave Maria, solicitando a proteção de Nossa Senhora (HOFFMANNHOROCHOVSKI, 2012).

Manuela não tem um espaço exclusivo para a sua prática, mas atende todos que a procuram na sala de sua casa, decorada com quadros sacros. Também "costura" machucaduras e rendiduras (torção, lesão por esforço, mau jeito), além de curar quebranto (mau-olhado) em crianças, dor de cabeça e dores no corpo. Diferentemente de Natália, recomenda chás e o uso de ervas como medicamento, muitas das quais podem ser encontradas em seu próprio quintal. Além disso, utiliza instrumentos diversos em seu ritual de cura, que varia de acordo com a causa do mal-estar. A dor de cabeça, por exemplo, não tem uma única causa, então não pode ter um único tratamento. Entretanto, o mais utilizado é com "broto de banana-maçã [...] a gente corta e abre ele e coloca na testa com pano para refrescar, refrescar. Daí puxa toda a dor de cabeça” (Manuela). Já no caso de ser proveniente de sol, ela utiliza um vidro com água e três dentes de alho, que coloca sobre um pano branco em cima da cabeça enquanto realiza a benzedura.

Mariana também receita ervas e utiliza instrumentos, além das orações faladas, para benzer pessoas com dor de cabeça, dor no corpo, cobreiros, "sapo de cova" (afta), entre outros; são arsenais, que juntamente com as rezas, permitem que ela realize "sua missão" de curar males corporais e espirituais (SILVA, 2009). Como exemplo, a faca é usada para curar a afta e a garrafa para a dor de cabeça. Numa situação específica, de um jovem com dor de cabeça extremamente forte, foram noves sessões para garantir a eficácia do benzimento. Tal como Manuela costuma fazer, utilizou uma garrafa - com água, três dentes de alho e arruda - 
para benzer a cabeça do rapaz, enquanto proferia suas rezas. Após o término do ritual de cura, como sempre acontece, sentiu-se renovada e recompensada, ou como costuma dizer, com "força" e "boas energias". Para ela, benzer é uma obrigação, mas também uma realização.

Esse mesmo sentimento motiva Diana na sua prática de cura. Além da reza, ela também utiliza plantas e principalmente as garrafadas, "remédios de ervas", para tratar doenças do corpo e do espírito. "Você tá com bronquite [...] eu pego poejo, eu pego folha de laranja, eu pego umas casquinhas que é um segredinho que eu tenho ali e faço a infusão [...] salva a bronquite, cura asma também” (Diana). Após ouvir as queixas do paciente, ela reza, se concentra e lembra qual é a planta indicada, bem como se é melhor fazer chá, banho ou garrafada. Mas admite que usualmente faz garrafada, sempre com água, nunca com álcool: "pra bronquite, pra artrose, artrite e essas coisas de velho assim, sabe? E pra dor de barriga, pra dor no útero, pra ter nenê, de fortificar o útero pra ter nenê eu sei fazer garrafada também [...] quanto nenê já veio fabricado por mim" (Diana).

Embora tenha diferenças nos procedimentos ritualísticos, nas rezas e nas recomendações, as benzedeiras pesquisadas apresentam em comum o objetivo de ajudar a todos que as procuram, sem pedir nada em troca, curando doenças do corpo e da alma ou recomendando a busca por tratamento médico, especializado. Elas sabem que dependendo da doença, as benzeduras, garrafadas e costuras não são suficientes para garantir a cura. Em outros termos, há doenças que não são "doenças de rezadeiras" (SANTOS, 2007), mas sim "doenças de médicos", que exigem tratamentos e medicamentos específicos.

Natália costuma intuir quando a benzeção não é suficiente e pede para a pessoa procurar com urgência a Unidade Básica de Saúde do bairro ou o hospital da cidade para consultar um médico. Diana concorda que em determinados casos de "doenças do corpo" a medicina é fundamental para o reestabelecimento da saúde. Manuela também orienta seus clientes a procurarem auxílio médico quando necessário. Conta a respeito de uma moça que seguiu seu conselho e descobriu que tinha uma grave doença no estômago. Depois de curada pela medicina, voltou para lhe agradecer. Mas afirma com serenidade que o contrário também pode ocorrer: o médico também pode sugerir ou mesmo procurar uma benzedeira. Conta, sem esconder o orgulho, que atendeu um médico curitibano que sequer conseguia andar por conta de uma "machucadura": “[...] desembarcaram ele daí do carro [...] tiraram ele pra ele vim aqui pra dentro e fazer remédio pra ele. E ele foi, e foi curado, e daí ele gostou muito...” 
(Manuela). Foi curado com o ritual da costura e com o uso de arnica, que atua como antinflamatório e é bom para cicatrização (HOFFMANN-HOROCHOVSKI, 2012).

Esse exemplo é bastante instigante, pois permite refletir sobre quem afinal procura as benzedeiras. Não são apenas pessoas "simples", oriundas da classe popular e que tradicionalmente tiveram pouco acesso à educação formal e ao saber médico. Pessoas instruídas, que se consultam frequentemente com médicos e que possuem uma situação financeira mais confortável também o fazem; é o caso de políticos, professores, profissionais da saúde, entre outras. Pessoas que acreditam nas benzedeiras, no poder das rezas, na eficácia das ervas... Pessoas que buscam a medicina popular como alternativa ou como uma forma de complementar o tratamento da medicina tradicional. Afinal, muitas pessoas vão ao médico e a benzedeira ao mesmo tempo (SANTOS, 2007).

A eficácia simbólica dessa prática está relacionada com alguns elementos que estão interligados: a crença no benzimento, na pessoa que o executa - detentora de um dom divino - e o reconhecimento da comunidade (LÉVI-STRAUSS, 2008; LIMA, 2001). A benzedeira tem uma legitimidade conferida pela comunidade, afinal ela não só conhece as rezas, fórmulas mágicas, como sabe utilizá-las. Muitas vezes ela recomenda também o uso de plantas medicinais. Muitas benzedeiras, a exemplo de Manuela, Diana e Mariana, conhecem suas propriedades por meio de um saber popular, transmitido oralmente de geração a geração. É comum trabalhar com as plantas que encontram em sua região, quando não no seu quintal (SILVA, 2009), tal como já registrado por Manuela.

Esse conhecimento tem sido resgatado e valorizado pela Etnobotânica, que procura compreender como a flora, especialmente as plantas medicinais, vem sendo utilizada empiricamente e quais os significados e crenças que a envolvem (MACIEL; GUARIM NETO, 2006; PASA, 2011). Recuperar e registrar esse saber popular no tratamento de doenças é assaz importante e pode fornecer subsídios para pesquisas com as plantas, bem como atuar na preservação da cultura.

Neste contexto, inserem-se rezadores, erveiros, benzedores e benzedeiras, estes como especialistas, que mantêm através de suas fórmulas e simbolismo nas rezas segredos dos vários usos acerca das plantas, tanto para fins medicinais na busca da cura de doenças do corpo, como para "banhos" visando à cura de "doenças da alma". Ressalta-se, aqui, que corpo e alma são ressignificados em universo plural, holístico, cósmico (MACIEL; GUARIM NETO, 2006, p. 64). 
É importante frisar, contudo, que a prescrição de ervas para banhos, chás, unguentos, por mais que ajudem no processo de cura, "são apenas um complemento. A essência da benzeção é a oração e o rito que envolve a prece. Assim, conclui-se que uma vez estabelecida a oração que incidirá na cura espiritual, as ervas e sua manipulação auxiliarão na cura física" (NOGUEIRA; VERSONITO; TRISTÃO, 2012, p. 172). Por isso, nem todas as benzedeiras, a exemplo de Natália, costumam fazer essas indicações; ficam no plano das orações. Por fim, resta destacar que a prática da benzeção é fundamentalmente ancorada na fé. Sua eficácia simbólica resulta da crença no poder da benzedura e nas pessoas que a executam, nos rituais, nas rezas e nas receitas que comumente envolvem plantas bem conhecidas pela população.

\section{Breves considerações finais}

As benzedeiras desenvolvem a importante função de serem "guardiãs da memória" (SILVA, 2009). Por meio de suas vozes que professam orações e contam histórias, a possibilidade de registrar uma prática enraizada na cultura brasileira e que por muito tempo era uma das principais alternativas de cura, quando não a única, dos grupos excluídos espacial, social e economicamente.

Tradicionalmente transmitida de geração a geração, a benzedura pode desaparecer na ausência de novos aprendizes, o que, diga-se de passagem, parece cada vez mais evidente, principalmente no meio urbano. Tanto que das benzedeiras aqui entrevistadas, somente Mariana, que vive numa pequena comunidade rural, tem na filha sua possível sucessora. O desinteresse dos jovens pode estar relacionado a vários fatores relacionados à atividade, entre os quais: caráter sacro, disponibilidade de tempo, desconhecimento, falta de remuneração, altruísmo. A valorização e divulgação desse conhecimento popular, não obstante, pode atrair a atenção das novas gerações e garantir sua continuidade.

Outro obstáculo que a prática enfrenta está relacionado às religiões evangélicas. Associada ao catolicismo popular, a benzeção tem sido condenada por crentes que questionam sua eficácia, bem como o uso de imagens ou a evocação dos santos. A relação dos evangélicos com as benzedeiras não é exatamente "amistosa" (SANTOS, 2007), posto que traduz um conflito simbólico (ARCHANJO; LEITE, 2014). Na região litorânea é comum ouvir relatos tanto sobre pessoas que deixaram de benzer após terem se convertido quanto 
sobre as que vão receber benzimento escondidas da família. A razão de fundo é a mesma: a prática não condiz com a fé evangélica. $\mathrm{Na}$ fala de Diana isso fica claro quando expõe, sem esconder a tristeza, que a filha não compreende seu dom, tampouco aceita suas garrafadas. "Ela não aceita. Então pra não brigar mais com ela eu não falo mais nesse assunto [...] Se chegar alguém naquela hora que a minha filha tá aqui digo depois você volta, mas que ela não veja" (Diana).

A prática também enfrenta conflitos na ordem do conhecimento. $O$ benzimento está atrelado a um saber popular, que se diferencia do conhecimento racionalizado e especializado da biomedicina. O saber médico geralmente tem reservas, quando não contraindicações, quanto a essa prática; desqualifica seu ritual de cura e acredita que ela pode inibir a busca por tratamento médico, especializado. Possíveis (e raras) tentativas de aproximação com a medicina popular exigem primeiramente a comprovação científica. É o caso das plantas, por exemplo. As práticas tradicionais de cura, por sua vez, sobrevivem sem recusar, ou melhor, "oferecer resistência" ao conhecimento biomédico (ARAÚJO, 2000). Convivem com ele e podem se reinventar a partir dele, sempre considerando a saúde como resultante do equilíbrio entre corpo e alma. Mesmo quando os pacientes não declaram ao médico, "as ervas continuam a fazer parte das práticas populares de cura” (ARAÚJO, 2000, p. 108). Assim como as benzeduras e costuras.

Talvez por isso mesmo, movimentos de registro, valorização e manutenção das práticas tradicionais de cura são cada vez mais presentes. É importante citar que como atividade de valorização e manutenção, o Movimento Aprendizes da Sabedoria (Masa) assume uma importância crucial na luta pelo reconhecimento desta prática.

O Masa nasceu com o intuito de possibilitar a comunicação entre as benzedeiras(os), curandeiras(os), costureiras(os) de machucaduras e rendiduras, rezadeiras(os), entre outros conhecedores de práticas populares de cura. A ideia básica era romper com preconceitos, fortalecer a atividade e lutar por seu reconhecimento. Entre as conquistas do movimento, destacam-se: a) o levantamento de todas(os) benzedeiras(os)/curandeiras(os) das cidades paranaenses de Rebouças e São João do Triunfo (133 e 161, respetivamente) e o reconhecimento oficial da atividade (SILVA, 2012); b) a conquista do prêmio Rodrigo Melo Franco de Andrade, do Instituto do Patrimônio Histórico e Artístico Nacional, na categoria "salvaguarda de bens de natureza imaterial" (IPHAN, 2011), pelo mapeamento das benzedeiras(os); c) a realização do $2^{\circ}$ Encontro das Benzedeiras do Centro-Sul do Paraná, em 
setembro de 2012. Apesar dessas inegáveis conquistas, a pauta de luta do Masa é ampla e inclui políticas de "reconhecimento formal e respeito" aos que desenvolvem ofício tradicional de cura, com livre acesso à coleta de plantas medicinais e seu acolhimento no sistema de saúde público. Ademais, propõe parcerias com instituições ambientais e de ensino para garantir "reflorestamento de espécies nativas medicinais em risco de extinção", sustentabilidade de recursos naturais e difusão da cultura local (MASA, 2012).

Iniciativas como essa fortalecem os saberes tradicionais e podem atuar significativamente na sua manutenção e divulgação. A luta, que ultrapassa fronteiras geográficas, é pela preservação da cultura, da história e da memória coletiva; é pelo respeito ao conhecimento da assim chamada medicina popular; é pela complementariedade entre os saberes no que tange ao processo saúde- -doença. E, obviamente, essa luta ganha força com estudos acadêmicos, como por exemplo os da Etnobotânica, que se debruçam sobre esses saberes desvendando as potencialidades das plantas comumente utilizadas nos processos de cura e os significados culturais inerentes ao processo.

Finalizam-se essas breves reflexões com as benzedeiras aqui apresentadas. São mulheres simples, sábias, que muito viveram, apreenderam e que, por extensão, têm muito o que contar. Mulheres que receberam um dom e assumiram o ofício sagrado de ajudar aos outros, curando males oriundos do corpo e do espírito. Mulheres, que como tantas outras (e também outros) de diferentes paragens, não concebem outra forma de viver: benzer é um dom, uma obrigação e uma realização. Benzer é a forma pela qual ajudam ao próximo e, concomitantemente, garantem a manutenção de uma atividade tradicional de cura. Benzer é uma prática que lhes garante a identidade, a sensação de pertencimento na comunidade, seu lugar no mundo!

\section{Referências}

ARAÚJO, F. L. Representações de doença e cura no contexto da prática popular da medicina: estudo de caso sobre uma benzedeira. Caos - Revista Eletrônica de Ciências Sociais, n. 18, p. 81-97, set. 2011. Disponível em:

<http://www.cchla.ufpb.br/caos/n18/9_FABIANO_ARAUJO_Representacoes_no_contexto_d o_benzimento.pdf>. Acesso em: 12 jun. 2012.

ARAÚJO, M. A. M. Bactrins e quebra-pedras. Interface: comunicação, saúde, educação, v. 4, n. 7, p. 103-10, 2000. Disponível em: 
$<$ http://www.scielo.br/pdf/icse/v4n7/08.pdf>. Acesso em: 16 jun. 2014.

ARCHANJO, L.R.; LEITE, D.A.T. A benzeção como prática terapêutica. In: RASIA, J.M; LAZZARETTI, C. T. Saúde e Sistema Único de Saúde: estudos socioanalíticos. Curitiba: Editora UFPR, 2014, p.237-249.

BRASIL. Lei $\mathbf{n}^{\mathbf{0}} \mathbf{8 . 0 8 0}$, de 19 de setembro de 1990. Lei Orgânica da Saúde. Dispõe sobre as condições para a promoção, proteção e recuperação da saúde, a organização e o funcionamento dos serviços correspondentes e dá outras providências. Disponível em $<$ http://www.planalto.gov.br/ccivil_03/leis/18080.htm>. Acesso em: 09 out. 2012.

BOSI, E. Memória e sociedade: Lembranças de velhos. 9. ed. São Paulo: Companhia das Letras, 2001.

CHEMIN, M. Constituição fisionômica e identidade visual em espaços de paisagens: um estudo de caso múltiplo em cidades turísticas do litoral do Paraná. 2011. 299 f. Tese (Doutorado em Geografia)- Universidade Federal do Paraná, 2011. Disponível em: $<$ http://www.litoral.ufpr.br/sites/default/files/Tese_Marcelo\%20CHEMIN.pdf $>$. Acesso em: 09 jul. 2014.

FIGUEIREDO, B. G. A arte de curar: cirurgiões, médicos, boticários e curandeiros no século XIX e Minas Gerais. 2. ed. Belo Horizonte: Argumentum, 2008.

HALBWACHS, M. A memória coletiva. São Paulo: Centauro, 2004.

HOFFMANN-HOROCHOVSKI, M. T. Velhas benzedeiras. Dossiê - O final da vida no século XXI. Revista Mediações, Londrina, vol. 17, n. 2, p. 126-140, jul./dez. 2012. Disponível em:

<http://www.uel.br/revistas/uel/index.php/mediacoes/article/viewFile/14025/11836>. Acesso em: 12 dez. 2013.

IPARDES - Instituto Paranaense de Desenvolvimento Econômico e Social. Municípios e regiões: perfil dos municípios. Curitiba, 2013. Disponível em:

$<$ http://www1.ipardes.pr.gov.br/index.php?pg_conteudo=1\&cod_conteudo=29>. Acesso em: 05 jul. 2014.

IPHAN - Instituto do Patrimônio Histórico e Artístico Nacional. Prêmio Rodrigo Melo Franco de Andrade. Categoria Salvaguarda de bens de natureza imaterial. Mapeamento social das benzedeiras dos municípios de São João do Triunfo e Rebouças do estado do Paraná. Proponente: Movimento dos Aprendizes da Sabedoria. Irati, 2011. Disponível em: $<$ http://portal.iphan.gov.br/portal/baixaFcdAnexo.do?id=1849>. Acesso em: 12 dez. 2013.

LÉVI-STRAUSS, C. O feiticeiro e sua magia In: Antropologia Estrutural. São Paulo: Cosac Naify, 2008.

LIMA, W. P. de. Reza e cura: uma etnografia de rezadores em Benjamin Constant Amazonas. In: ENCONTRO ANUAL DA ANPOCS, GT 31 - Saúde, emoção e moral. 35., 2011, Caxambu. Anais... Caxambu, 2001. Disponível em: 
$<$ www.sigeventos.com.br/anpocs/inscricao/resumos/.../TBR0405-1.DOC $>$. Acesso em: 25 jun. 2014.

MACIEL, M. R. A; GUARIM NETO, G. Um olhar sobre as benzedeiras de Juruena (Mato Grosso, Brasil) e as plantas usadas para benzer e curar. Boletim do Museu Paraense Emílio Goeldi. Ciências Humanas, Belém, v. 1, n. 3, p. 61-77, set./dez. 2006. Disponível em: $<$ http://www.scielo.br/pdf/bgoeldi/v1n3/v1n3a03.pdf>. Acesso em: 25 jun. 2014.

MAGNANI, J. G. O velho e bom caderno de campo. Revista Sexta Feira, n. 1, p. 8-12, maio 1997.

MASA (Org.). Boletim informativo nova cartografia social dos povos e comunidades tradicionais do Brasil - Conhecimentos tradicionais e mobilizações políticas: o direito de afirmação da identidade de benzedeiras e benzedores, municípios de Rebouças e São João do Triunfo, Paraná. Edição Especial, abril de 2012. Manaus: Editora da Universidade Estadual do Amazonas, 2012.

NOGUEIRA, L. C.; VERSONITO, S.; TRISTÃO, B. das D. O dom de benzer: a sobrevivência dos rituais de benzeção nas sociedades urbanas - O caso do município de Mara Rasa, Goiás, Brasil. Élisée, Rev. Geo. UEG, Goiânia, v. 1, n. 2, p. 167-181, jul./dez. 2012. Disponível em: <http://www.prp.ueg.br/revista/index.php/elisee/article/view/1290>. Acesso em: 16 jun. 2014.

PASA, M. C. Saber local e medicina popular: a etnobotânica em Cuiabá, Mato Grosso, Brasil. Boletim do Museu Paraense Emílio Goeldi. Ciências Humanas, v. 6, n. 1, p. 179-196, jan./abr. 2011. Acesso em: 25 jun. 2014.

SANTOS, F. V. dos. O ofício das rezadeiras: um estudo antropológico sobre as práticas terapêuticas e a comunhão de crenças em Cruzeta/RN. 2007. Dissertação (Mestrado em Antropologia Social)- Universidade Federal do Rio Grande do Norte, 2007.

SILVA, C. S. da. Rezadeiras: guardiãs da memória. ENECULT - ENCONTRO DE ESTUDOS MULTIDISCIPLINARES EM CULTURA, 5., 2009, Salvador. Anais... Salvador: UFBA, 2009. Disponível em: <http://www.cult.ufba.br/enecult2009/19161.pdf>. Acesso em: 21 jul. 2014.

SILVA, M. K. Uma introdução à história oral. Cadernos de Sociologia, Porto Alegre, v. 9, 1998.

SILVA, M. G. Ajuda pelo toque das mãos. Gazeta do Povo. Vida e cidadania. Curitiba, 02/05/2012. Disponível em: $<$ http://www.gazetadopovo.com.br/vidaecidadania/conteudo.phtml?id=1250174>. Acesso em: 05 jul. 2012.

Artigo recebido em 25/11/2015. Aceito para publicação em 27/01/2016. 